\title{
Substrate Temperature Constrains Recruitment and Trail Following Behavior in Ants
}

Louise van Oudenhove \& Raphaël Boulay \&

Alain Lenoir \& Carlos Bernstein \& Xim Cerda

\begin{abstract}
In many ant species, foragers use pheromones to communicate the location of resources to nestmates. Massrecruiting species deposit long-lasting anonymous chemical trails, while group-recruiting species use temporary chemical trails. We studied how high temperature influenced the foraging behavior of a mass-recruiting species (Tapinoma nigerrimum) and a group-recruiting species (Aphaenogaster
\end{abstract}

Electronic supplementary material The online version of this article (doi:10.1007/s10886-012-0130-x) contains supplementary material, which is available to authorized users.

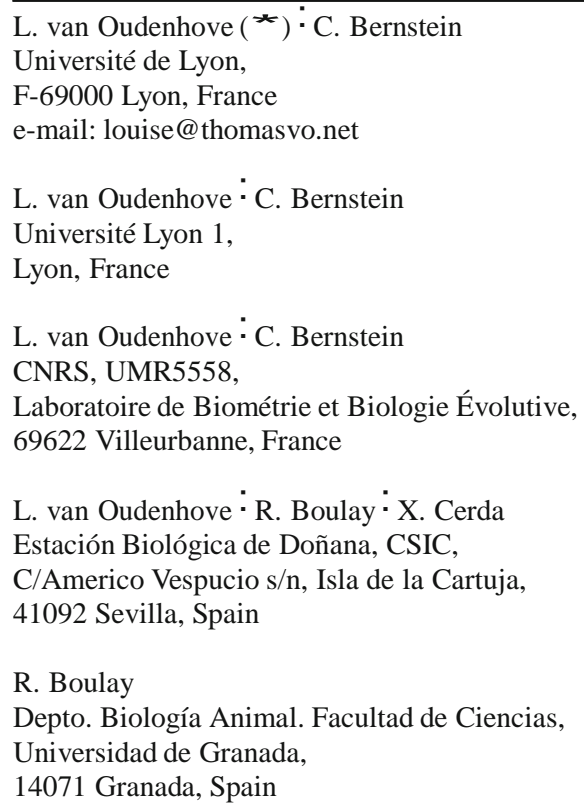

\section{A. Lenoir}

CNRS UMR7261, Institut de Recherche de Biologie de l'Insecte, Faculté des Sciences de Techniques, Université François Rabelais, Parc de Grandmont,

37200 Tours, France senilis) through pheromone decay. First, under controlled laboratory conditions, we examined the effect of temperature on the trail pheromone of both species. A substrate, simulating soil, marked with gaster extract was heated for $10 \mathrm{~min}$. at $25^{\circ}, 35^{\circ}, 45^{\circ}$, or $55^{\circ} \mathrm{C}$ and offered to workers in a choice test. Heating gaster extract reduced the trail following behavior of the mass-recruiters significantly more than that of the group-recruiters. Second, analyses of the chemicals present on the substrate indicated that most $\mathrm{T}$. nigerrimum gaster secretions vanished at $25{ }^{\circ} \mathrm{C}$, and only iridodials persisted up to $55{ }^{\circ} \mathrm{C}$. By contrast, A. senilis secretions were less volatile and resisted better to elevated temperatures to some extent. However, at $55{ }^{\circ} \mathrm{C}$, the only chemicals that persisted were nonadecene and nonadecane. Overall, our results suggest that the foraging behavior of the group-recruiting species A. senilis is less affected by pheromone evaporation than that of the mass-recruiting species $T$. nigerrimum. This group-recruiting species might, thus, be particularly adapted to environments with fluctuating temperatures.

Keywords Ant communities · Trail pheromone · Temperature · Competition · Tapinoma nigerrimum . Aphaenogaster senilis

\section{Introduction}

Communities of ants, like those of many other organisms, are often characterized by the diversity of coexisting species. It is, therefore, fundamental to understand the factors that allow species coexistence at the community level (Andersen, 2008). Niche partitioning is a well-known mechanism that mediates competitive exclusion (Albrecht and Gotelli, 2001). Co-occurring species might differ in their 
nesting requirements (Torres, 1984), diet (Cerdá et al., 1998b; Sanders and Gordon, 2003; Blüthgen and Fiedler, 2004; Lebrun, 2005), foraging schedules, and/or resistance to environmental stress (Savolainen and Vepsäläinen, 1989; Hölldobler and Wilson, 1990; Cros et al., 1997; Retana and Cerdá, 2000). In environments with fluctuating temperatures, species with different thermal tolerance tend to segregate temporally in their foraging activity. In Iberian Mediterranean communities for instance, the two co-occurring species Tapinoma nigerrimum and Aphaenogaster senilis compete for arthropod corpses (Cerdá et al., 1998b), differ in their thermal preferences (Cerdá et al., 1998a), and field observations show that during the hot summer days, the former tends to forage at night while the latter is more abundant during the day (Cros et al., 1997).

In ants, foraging behavior can vary from being more individual to more social (Traniello, 1989). Although a few species forage individually without communicating food location to nestmates (e.g., Cataglyphis spp., Wehner et al., 1983, Lenoir et al., 1990, 2009; or Pachycondyla, Fresneau, 1985), the great majority of ants rely on recruitment to exploit food sources (Wilson, 1971). Recruitment processes can involve a combination of cues ranging from physical contact, stridulation, and pheromones (Hölldobler and Wilson, 1990). In many species, scouts, who search the environment for food, deposit a pheromone trail upon food discovery. This pheromone trail communicates information about resource location to nestmates. In a self-amplifying process, recruits often become recruiters as they contribute to trail reinforcement. Recruitment behavior can be classified according to the complexity of communication it requires (Wilson, 1971; Beckers et al., 1989). In group recruitment (e.g., Camponotus socius, Hölldobler, 1971; Kohl et al., 2001), a small group of recruits follows a recruiter while it returns from the nest to the resource. By contrast, massrecruitment (e.g., Lasius niger, Beckers et al., 1992) does not involve a leader (Bonabeau et al., 1998): it implies independent trail-laying and trail-following behavior. Both group and mass recruitment allow the adjustment of the collective response to a given environment (Detrain and Deneubourg, 2002; Cerdá et al., 2009). On the one hand, group recruitment permits the rapid mobilization of nestmates to exploit a wide range of food items (Cerdá et al., 2009). On the other hand, mass recruitment seems particularly efficient for longer lasting resources. By recruiting a huge number of workers to food sources, mass recruiting species are able to monopolize resources against competitors (Jaffe, 1980). In a competitive context, mass recruitment is, therefore, associated with behavioral dominance.

Temperature is an essential dimension of what Hölldobler and Wilson (1990) call the "temperature-humidity envelope" that determines the microenvironment favorable to the foraging activity of ants. In many communities, behaviorally subordinate species are more tolerant of stressful temperatures than their competitors (Cerdá et al., 1998a; Bestelmeyer, 2000; Lessard et al., 2009; Wittman et al., 2010). For example, in arid or semi-arid ant communities, subordinate species show behavioral (gaster raising in Cataglyphis rosenhaueri, Cerdá and Retana, 2000, Lenoir et al., 2009), morphological (long legs as shown by Stefan and Wehner (2012), larger workers are less subject to desiccation, Lighton and Feener, 1989), and/or biochemical (heat shock proteins synthesis, Gehring and Wehner, 1995) adaptations to arid environments. These apparent adaptations to stressful environments might result from character displacement, allowing these species to forage when ground temperature is suboptimal for their competitors. However, the constraints that prevent such thermal tolerance to evolve in dominant species remain unclear. Since behavioral dominance relies on the control of resources against competitors, we hypothesized that the efficiency of the recruitment process could be such a constraint.

As with many terrestrial invertebrates, ants maintain an intimate relationship with soil (see Vander Meer, 2012, this issue). In different Formicidae subfamilies, species that use chemical recruitment tend to forage at lower temperatures than species that do not (Ruano et al., 2000). This pattern might be due to the volatility of the trail pheromones. Indeed, high temperatures, by accelerating pheromone decays, limit trail-following behavior (van Oudenhove et al., 2011). The purpose of the present study was to determine whether high temperatures affected differently the foraging activity of ant species according to their recruiting system. In particular, we hypothesized that pheromone volatility limits recruitment behavior more in mass-recruiting species than in grouprecruiting species. We tested this hypothesis with two widespread competing species in Iberian Mediterranean communities: Tapinoma nigerrimum and Aphaenogaster senilis. The former is a mass-recruiting species (Cerdá et al., 1989; Blight et al., 2010), whereas the latter uses group recruitment (Cerdá et al., 2009). To clarify the overall effect of high temperature on the foraging behavior of both species, we conducted a laboratory experiment in which gaster extracts were subjected to increasing temperatures. This approach allowed us to compare the rate at which trail pheromone dissipates as a function of ground temperature and independently of ant body temperature. Finally, we analyzed the composition of the gaster extracts and determined how they were altered by high temperatures.

\section{Materials and Methods}

Model Species and Study Sites Tapinoma nigerrimum is a highly polygynous, polydomous, and dominant species whose colonies contain tens of thousands of workers (Cerdá et al., 1989, 1997). Workers collect mainly aphid honeydew, 

and, to a lesser extent, arthropod corpses (Cerdá et al., 1989). Their trail pheromone originates from the pygidial gland located in the gaster (Pavan and Trave, 1958; Simon and Hefetz, 1991). Tapinoma nigerrimum is a heatintolerant species: its Maximal Activity Temperature is $24{ }^{\circ} \mathrm{C}$ and its Critical Thermal Limit is $42{ }^{\circ} \mathrm{C}$ (Cerdá et al., 1998a). In contrast, A. senilis is a strictly monogynous, monodomous, and subordinate species whose colonies contain 1,300 workers on average (Boulay et al., 2007a). It is an opportunistic, omnivorous species that feeds on dead arthropods and a variety of vegetative items including petals and seeds (Boulay et al., 2007b). Workers use group-recruitment when food items are not transportable by individual foragers (Cerdá et al., 2009). The trail pheromone is composed of a mixture of alkaloids and hydrocarbons secreted by the Dufour and venom glands (Lenoir et al., 2011). It is a thermophilic species whose Maximal Activity Temperature and Critical Thermal Limit are $42{ }^{\circ} \mathrm{C}$ and $46{ }^{\circ} \mathrm{C}$, respectively (Cerdá et al., 1998a).

Laboratory experiments were conducted in spring 2009 with ants freshly collected from the field in southern Spain (Doñana National Park), and transferred to artificial nests. For A. senilis, medium-sized queenright colonies (about 1,000 workers and abundant brood) were used. For T. nigerrimum, partial colonies $(1,000-5,000$ workers) with one or several queens were used. We employed 6 colonies of each species in our experiments. Artificial nests consisted of plastic boxes, the bottoms of which were coated with plaster to maintain humidity and simulate soil conditions. Testtubes $(2 \times 20 \mathrm{~cm})$ that were half-filled with water and plugged with cotton also were placed in the nests to maintain humidity. Room temperature and humidity remained constant over the course of the experiment, at $25{ }^{\circ} \mathrm{C} \pm 1{ }^{\circ} \mathrm{C}$ and $35 \% \pm 5 \%$, respectively. Ants were fed three times a week with meal worms (Tenebrio molitor). All experiments were conducted after colonies had fasted for $2 \mathrm{~d}$.

Effect of High Temperature on Ant Behavioral Response Gaster secretions were obtained by excising the gasters of 20 chilled ants and then extracting their compounds over $24 \mathrm{~h}$ by using $400 \mu \mathrm{l}$ hexane. This extract then was diluted to obtain the different concentrations $(1: 1,1: 10,1: 100 \mathrm{v}: \mathrm{v}$ extract:hexane). Experiments were conducted every day with fresh extracts.

For both species, a trail of $10 \mu \mathrm{l}$ of gaster extract was manually deposited on a $2 \mathrm{~cm}$ wide, $25 \mathrm{~cm}$ long test glass bridge (bridge $\mathrm{X}$, hereafter) using a needle; $10 \mu \mathrm{l}$ of pure hexane were laid on a control glass bridge (bridge $\mathrm{C}$, hereafter). Bridges $X$ and $C$ were maintained for $10 \mathrm{~min}$ at $25,35,45$, or $55^{\circ} \mathrm{C}$. Both bridges then were cooled to room temperature $\left(25^{\circ} \mathrm{C}\right.$ ) for $5 \mathrm{~min}$. In order to test whether the ants were able to choose the previously marked bridge, a Y-shaped device was set-up with bridges $\mathrm{X}$ and $\mathrm{C}$ as the diverging branches; neither bridge lead to food. The location of both bridges (either left or right arm of the Y) was randomly chosen before each trial. Following the connection of the bridges to their foraging area, the number of ants crossing each branch was counted for 2 min. Five replicates were conducted per colony (N06 colonies per species), temperature, and extract concentration.

The probability of an ant choosing bridge $\mathrm{X}$ was analyzed by fitting a GLZ. The dependent variable was the number of ants crossing bridge $\mathrm{X}$ (success) and $\mathrm{C}$ (failure). Predictor variables were the species (2-level categorical variable), the treatment temperature (4-level categorical variable), and the dilution level of the extract (3-level categorical variable). A full GLZ including all effects and interactions was fitted using the quasi-binomial family. Non-significant interactions were progressively removed in accordance with F-test scaled deviances (see Supplemental Material 1 for model selection). Statistical analyses were performed using the R software (R Development Core Team, 2010).

\section{Abdominal Gland Secretions}

Gaster Extract Composition The abdomens of 10 to 20 freshly freezer-killed T. nigerrimum workers were placed in $1 \mathrm{ml}$ of hexane for $24 \mathrm{~h}$ to extract the relevant compounds. The extract was concentrated to $100 \mu \mathrm{l}$ under nitrogen flow and $2 \mu \mathrm{l}$ were injected into a Perkin-Elmer GC-MS operating at $70 \mathrm{EV}$ with a DB-5 fused silica capillary column (length $30 \mathrm{~m}$, inner diam $0.25 \mathrm{~mm}$, and film thickness $0.10 \mu \mathrm{m})$. Oven temperature was 1 ) held at $50{ }^{\circ} \mathrm{C}$ for $5 \mathrm{~min}, 2$ ) raised to $150{ }^{\circ} \mathrm{C}$ at a rate of $5^{\circ} \mathrm{C} / \min 3$ ), then raised to $320^{\circ} \mathrm{C}$ at rate of $15{ }^{\circ} \mathrm{C} / \mathrm{min}$, and 4 ) held at $320^{\circ} \mathrm{C}$ for the last $5 \mathrm{~min}$. This program enabled us to separate mostly volatile compounds [presumably originating from the pygidial gland as in $\mathrm{T}$. simrothi as described by Simon and Hefetz (1991)] from mostly non-volatile cuticular hydrocarbons. Twelve replicates were analyzed to obtain the relative chemical composition of the gaster extracts. Compound quantification was achieved by adding $400 \mathrm{ng}$ of Eicosane as an internal standard to the extracts before running the GC-MS.

The trail pheromone of Aphaenogaster senilis is composed of a mixture of secretions from the Dufour and poison glands (Lenoir et al., 2011). The former mostly contains hydrocarbons (Boulay et al., 2007a), while the latter contains significant amounts of alkaloids (Lenoir et al., 2011). We verified that the profiles of our experimental colonies were identical to those previously described for this species.

Compound Volatility Initial gaster exudate solutions were extracted from 150 gasters excised from chilled ants and placed in $1 \mathrm{ml}$ hexane for $24 \mathrm{~h}$. A first chromatography run was performed using $20 \mu \mathrm{l}$ of the initial extract diluted with $1.4 \mathrm{ml}$ dichloromethane ("extract" solution). To obtain the "control" solution, $20 \mu \mathrm{l}$ of the initial solution were 
deposited on a glass slide with a needle; the glass slide was immediately washed with $1.4 \mathrm{ml}$ dichloromethane, and the retrieved solution was analyzed in GC-MS. The aim of the "extract" and "control" solutions was to identify the compounds too volatile to be recovered after deposition on the glass slide. With the temperature-treatment solutions, $20 \mu \mathrm{l}$ of the initial solution were deposited on a glass slide with a needle; the glass slide was maintained at $25,35,45$, or $55^{\circ} \mathrm{C}$ for 10 min before being washed with $1.4 \mathrm{ml}$ dichloromethane and analyzed in GC-MS.

Before analytical chromatography was performed, $5 \mu$ l of C24 $\left(375.10^{-5} \mathrm{mg}\right)$ were added as an internal standard. Compounds were separated using a gas-chromatograph (GC-2010 Shimadzu) with a DB-5HT fused silica capillary column (length $30 \mathrm{~m}$, inner diam $0.25 \mathrm{~mm}$, and film thickness $0.10 \mu \mathrm{m}$ ). The temperature 1 ) was set at $50^{\circ} \mathrm{C}$ for the first $2 \mathrm{~min}, 2$ ) raised to $200{ }^{\circ} \mathrm{C}$ at a rate of $10{ }^{\circ} \mathrm{C} / \mathrm{min}$, 3) increased to $300{ }^{\circ} \mathrm{C}$ at rate of $20^{\circ} \mathrm{C} / \mathrm{min}$, and held at $300{ }^{\circ} \mathrm{C}$ for the last $5 \mathrm{~min}$.

Only compounds for which the concentration was higher than $10 \mathrm{ng}$ in $1.4 \mathrm{ml}$ of the extract solution were used in statistical analyses. Removed small peaks represent $12.69 \%$ (sd01.92) for A. senilis, and $10.87 \%$ (sd05.75) for $\mathrm{T}$. nigerrimum of the total amount of chemicals. For both species, compounds were regrouped into 4 categories according to their retention time. First, a Friedman rank sum test was performed to compare the total amount of compounds (irrespective of the category) in the initial extract and in the 5 retrieved solutions (control, 25, 35, 45, and $55^{\circ} \mathrm{C}$ ). Then, if any significant differences were detected, Kruskal-Wallis rank sum tests were performed on each category of compounds. The same procedure was repeated for all temperature-treatment solutions $\left(25,35,45\right.$, and $\left.55^{\circ} \mathrm{C}\right)$.

\section{Results}

Effect of High Temperature on Ant Behavioral Response At $25{ }^{\circ} \mathrm{C}$, significantly more workers of both species chose bridge $\mathrm{X}$ (previously marked) than bridge $\mathrm{C}$ (control) $\left(\mathrm{t}_{216}\right.$ 04.3, $\mathrm{P}<0.001$ for $\mathrm{A}$. senilis and $\mathrm{t}_{216}$ 08.0, $\mathrm{P}<0.001$ for $\mathrm{T}$. nigerrimum). The choice was more consistent over trials with T. nigerrimum than with A. senilis (Fig. 1). In both species, ants were less likely to choose bridge $\mathrm{X}$ at higher temperatures $\left(F_{3,236} 016.8, P<0.001\right.$; Fig. 2). However, at low extract concentrations, $\mathrm{T}$. nigerrimum was more affected by temperature increases than A. senilis (Fig. 2). The dilution level of the gaster extract was essential to predicting the probability of ants choosing bridge $\mathrm{X}$. The interaction between dilution and temperature effects was significant and different between the two species (Fig. 2). In T. nigerrimum, workers' choosiness significantly decreased with pheromone exudate dilution. At the highest

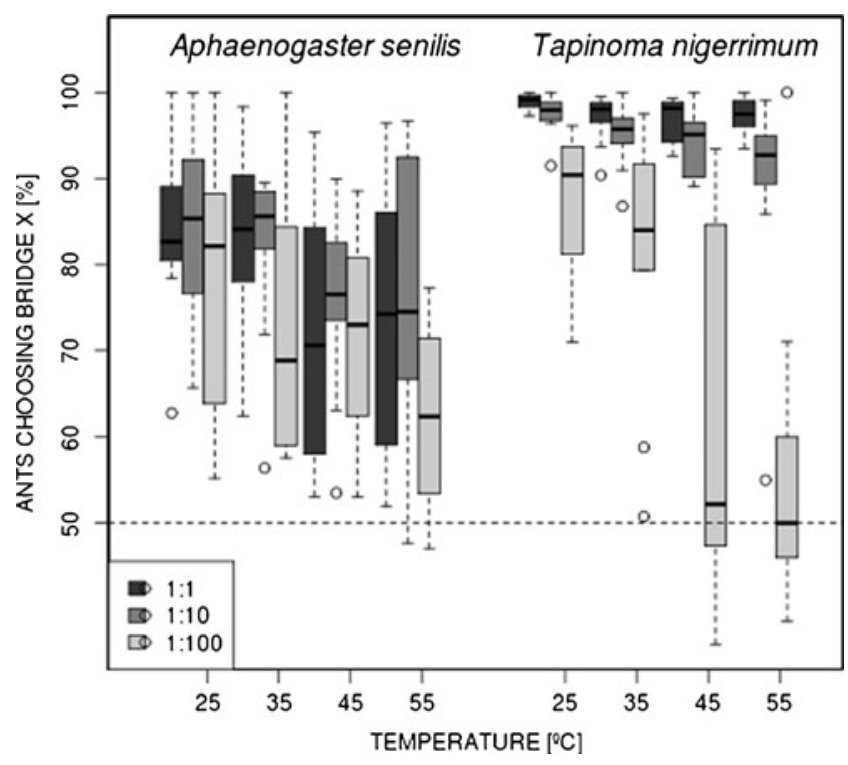

Fig. 1 Box plots of the proportion of Aphaenogaster senilis and Tapinoma nigerrimum workers choosing the chemically marked bridge (X) based on the temperature treatment and the dilution level of the gaster extract (1:1, 1:10, and 1:100, see insert). For each species, extract dilution, and temperature treatment, n 010 . The box represents $\pm 25 \%$ of the data, the bold line marks the median value, and vertical dot lines stand for the acceptable range $( \pm 1.5 *$ interquartile distance)

extract concentration (1:1), the temperature treatment had no effect on ant choice. At the lowest extract concentration (1:100), ants preferentially chose the marked bridge after mild temperature treatments but failed to discriminate between bridges after high temperature treatment (Fig. 2). Although A. senilis was not sensitive to differences in more
A. senilis

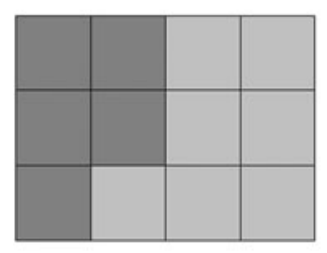

$\begin{array}{llll}25 & 35 & 45 & 55\end{array}$

Treatment temperature $\left[{ }^{\circ} \mathrm{C}\right]$
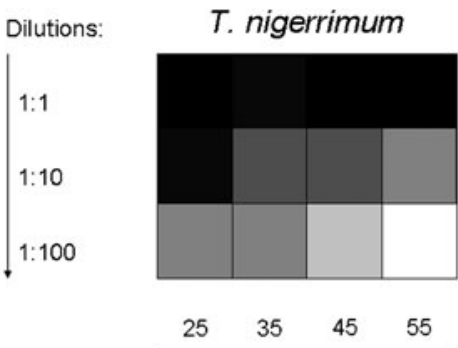

Treatment temperature $\left[{ }^{\circ} \mathrm{C}\right]$
Probability of choosing the marked bridge $X$ (from GLM estimates)

\begin{tabular}{|l|llll|}
\hline n.s. & & & & \\
\hline & 0.5 & 0.75 & 0.90 & 0.95 \\
\hline
\end{tabular}

Fig. 2 Probability of choosing the marked bridge $\mathrm{X}$ by workers of each ant species during experiments. Trail-following probability was estimated from the GLZ as a function of the species, the dilution level of the gaster extract, and the temperature treatment. The GLZ maximum-likelihood estimates were transformed with logistic function in order to represent the estimated probability of choosing the previously marked bridge $\mathrm{X}$ for the two species Aphaenogaster senilis and Tapinoma nigerrimum 
concentrated dilutions (1:1 vs. 1:10, Fig. 2), ant choice was significantly biased when exposed to greater dilution differences (1:10 vs. 1:100, Fig. 2).

\section{Abdominal Gland Secretions}

Gaster Extract Composition Gaster compounds extracted from $\mathrm{T}$. nigerrimum were dominated by significant amounts of monoterpene iridodial isomers (63.05 \% \pm 8.09 ; Fig. 3), ketones (2-methyl-4-heptanone, 6-methyl-5-hepten-2-one (sulcatone), 4-nonanone, and tridecanone, $29.38 \% \pm 8.27$ ), and iridomyrmecins (7.16 \% \pm 4.05$)$. Some alkanes, alkenes, and alcohols also were present in small quantities. The average quantity of each compound per individual was variable most likely due to worker polymorphism. There was about $116.7 \pm 19.1 \mathrm{ng}$ of light ketones, $259.7 \pm 56.3 \mathrm{ng}$ of iridodials, and $21.5 \pm 5.4 \mathrm{ng}$ of iridomyrmecins per individual.

We confirmed that the chemical profile of A. senilis abdominal glands was identical to that previously obtained for this species (Lenoir et al., 2011). The abdominal gland secretions of A. senilis were mostly composed of hydrocarbons and copious amounts of alkaloids.

Compound Volatility To study their stability at high temperatures, main compounds were grouped according to their retention times. For T. nigerrimum, the first group consisted of the light ketones (2-methyl-4-heptanone, 6-methyl-5hepten-2-one (sulcatone), 4-nonanone): they were highly volatile since they did not persist once deposited (presence in the extract solution and absence in the control solution,
Fig. 4b). Iridomyrmecins formed the second group. The third group contained 2-tridecanone. Both Iridomyrmecins and 2-tridecanone were of short durability since they persisted once laid, but dissipated in less than 10 min (presence in the control solution and absence in the $25{ }^{\circ} \mathrm{C}$ treatment, Fig. 4b). The fourth group was composed of stable aldehydes, the iridodials. Their quantity did not vary across all treatments (Table 1).

Regarding A. senilis gaster extract, we confirmed that the chemical profile of A. senilis abdominal glands was identical to that previously obtained for this species (Lenoir et al., 2011). The abdominal gland secretions of A. senilis were composed mostly of hydrocarbons and copious amounts of alkaloids. The main compounds were grouped according to their retention times and volatility. First, tridecane (C13) was found in small concentrations ( $<250 \mathrm{ng}$ per sample), rapidly vanished as temperature increased, and could not be detected after the bridge was heated to $55{ }^{\circ} \mathrm{C}$ (Table 2, Fig. 4a). Second, pentadecene and pentadecane coeluted with two alakaloids pyrazine and anabaseine. Both alkanes originated from the Dufour gland, while the alkaloids originated from the poison gland. Their concentration decreased rapidly with increasing temperature (Fig. 4a). They disappeared completely from $35{ }^{\circ} \mathrm{C}$ onwards (Fig. 4a). Third, three $\mathrm{C} 17$ alkanes and alkenes showed the same qualitative pattern as the second group, but their initial quantity was lower and they totally disappeared at $55{ }^{\circ} \mathrm{C}$ (Fig. 4a). The fourth group was stable and the quantity of compounds did not change between the different treatments (Table 2). It was formed by a mixture of nonadecene and nonadecane.

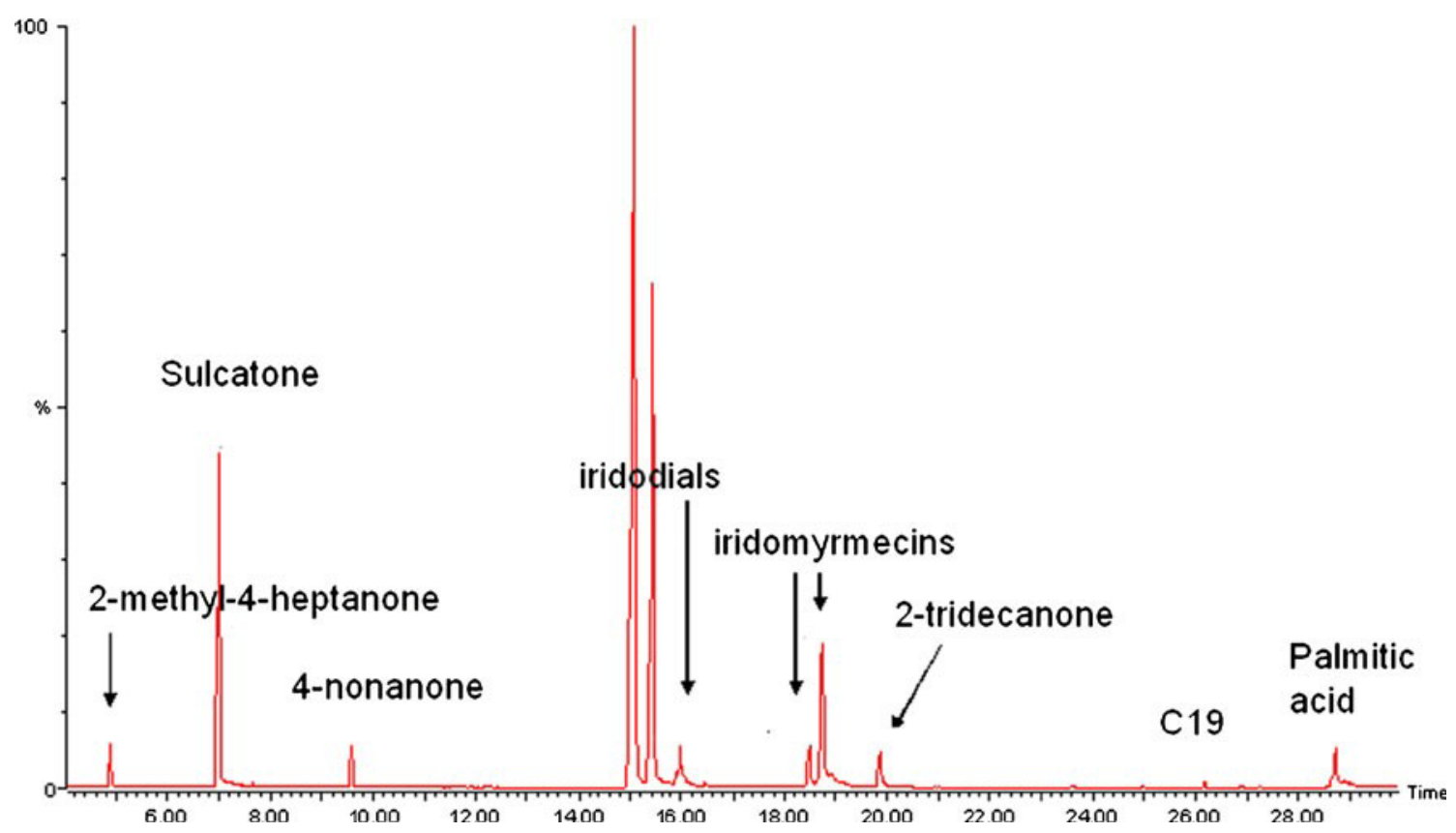

Fig. 3 Chromatogram of Tapinoma nigerrimum worker gaster extract obtained from GC-MS. The most abundant compounds are indicated 

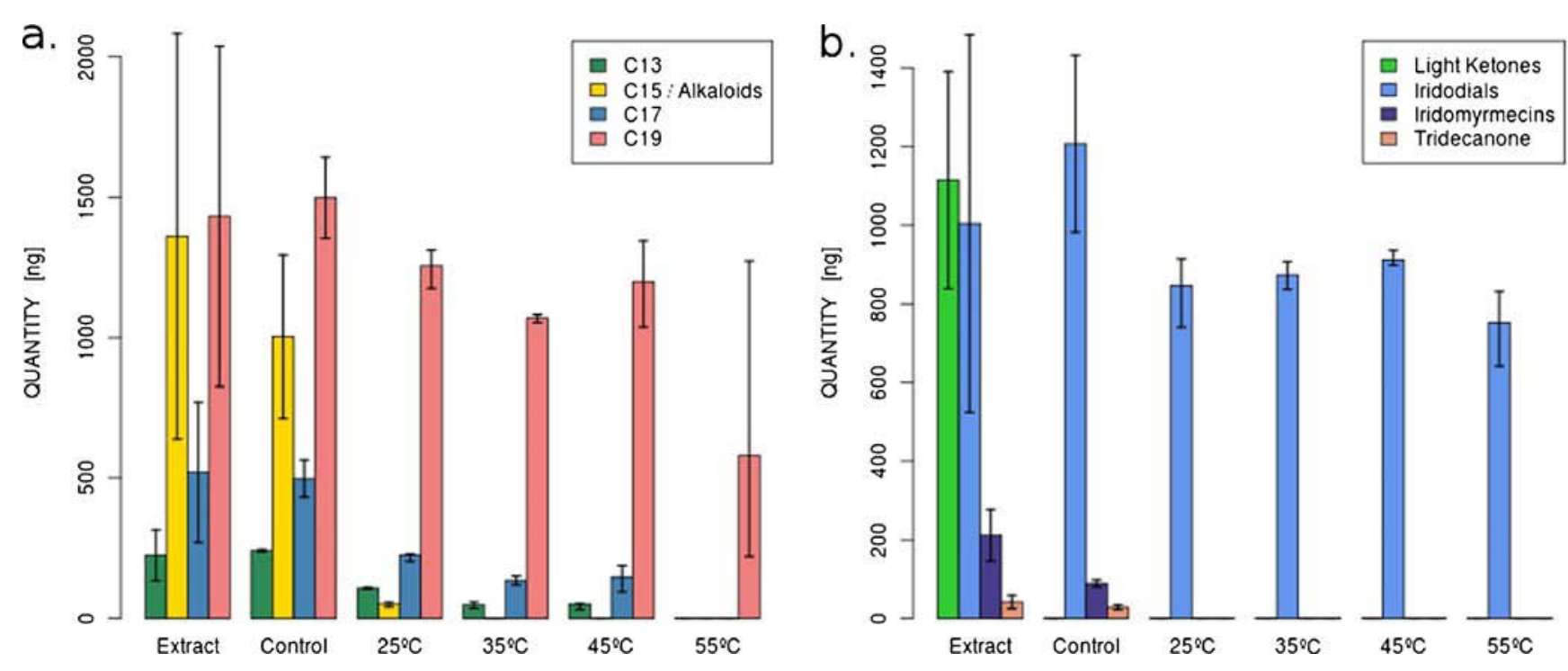

Fig. 4 Variation in (a) Aphaenogaster senilis and (b) Tapinoma nigerrimum worker gaster exudate composition across the different experimental treatments. The different solutions were analyzed by gas-chromatography using an initial concentration of 3 gasters

\section{Discussion}

High temperature differently affected the foraging behavior of Aphaenogaster senilis and Tapinoma nigerrimum. Trailfollowing experiments demonstrated that exposing gaster extract to increasing temperatures affected T. nigerrimum worker behavior more than A. senilis. Chemical analyses determined the composition of the gaster extract of both species and discriminated between the volatility of their different compounds. Linking chemical analyses and behavioral experiments allows one to identify the essential compounds for trail following behavior in both species.

Table 1 Volatility of the compounds involved in Tapinoma nigerrimum worker gaster exudate composition. "All solutions" tests identify absolute differences in concentration between the initial extract solution (initial concentration equivalent to 3 gasters), the control solution (laid and immediately retrieved from a glass bridge), and temperature treatments $\left(10 \mathrm{~min}\right.$. at $25,35,45$, or $55^{\circ} \mathrm{C}$ on a glass bridge). "Temperature treatments" test identifies differences in concentration exclusively due to temperature raising. Nonparametric tests were performed on the quantity of the compounds established by gas-chromatography

\begin{tabular}{lllll}
\hline Discriminating effect & Test & Df & $X_{2}$ & P-value \\
\hline All solutions & & & & \\
All compounds & Friedman & 15 & 36.9 & 0.001 \\
Ketones & Kruskal-Wallis & 5 & 14.9 & 0.011 \\
Iridodials & Kruskal-Wallis & 5 & 7.0 & 0.220 \\
$\begin{array}{l}\text { Iridomyrmecins } \\
\text { Tridecanone }\end{array}$ & Kruskal-Wallis & 5 & 14.9 & 0.011 \\
Temperature treatments & Kruskal-Wallis & 5 & 14.7 & 0.012 \\
All compounds & Friedman & 11 & 11 & 0.443 \\
\hline
\end{tabular}

The analysis of T. nigerrimum extract composition revealed the presence of remarkably stable compounds: the iridodials. These compounds also are involved in the recruitment process of a closely related species, Tapinoma simrothi, and have a half-life of 11 days (Simon and Hefetz, 1991). The strong persistence of this pheromone and an excellent trail following behavior ( $>90 \%$ of workers, Fig. 1) might be advantageous in the exploitation of stable food sources such as aphid-honeydew (Cerdá et al., 1989).

Table 2 Volatility of the compounds involved in Aphaenogaster senilis worker gaster exudate composition. "All solutions" tests identify absolute differences in concentration between the initial extract solution (initial concentration equivalent to 3 gasters), the control solution (laid and immediately retrieved from a glass bridge), and temperature treatments (10 min. at $25,35,45$, or $55^{\circ} \mathrm{C}$ on a glass bridge). "Temperature treatments" tests identify differences in concentration exclusively due to temperature raising. Nonparametric tests were performed on the quantity of the compounds established by gas-chromatography

\begin{tabular}{lllrr}
\hline Discriminating effect & Test & Df & X2 & P-value \\
\hline All solutions & & & & \\
All compounds & Friedman & 15 & 51.2 & $<0.001$ \\
C13 & Kruskal-Wallis & 5 & 13.9 & 0.016 \\
C15/alkaloids & Kruskal-Wallis & 5 & 14.6 & 0.012 \\
C17 & Kruskal-Wallis & 5 & 14.0 & 0.016 \\
C19 & Kruskal-Wallis & 5 & 6.8 & 0.233 \\
Temperature treatments & & & & \\
All compounds & Friedman & 11 & 35.1 & $<0.001$ \\
C13 & Kruskal-Wallis & 3 & 9.5 & 0.023 \\
C15/alkaloids & Kruskal-Wallis & 3 & 10.7 & 0.013 \\
C17 & Kruskal-Wallis & 3 & 9.6 & 0.022 \\
C19 & Kruskal-Wallis & 3 & 4.1 & 0.248 \\
\hline
\end{tabular}


Notwithstanding, despite this compound's stability, the ants' detection of the gaster extract failed under disadvantageous conditions (low gaster extract concentration and temperature treatments $>35^{\circ} \mathrm{C}$ ). Indeed, to induce optimal trail-following, traces of the more volatile compounds might be necessary, as in many other ant species (Morgan, 2009). To efficiently forage at high temperatures, the trail might, thus, necessitate constant reinforcement. In order to do so, foragers would risk exposure to higher temperatures. Consequently, the strong limitation placed by temperature on the foraging schedule of $\mathrm{T}$. nigerrimum might depend on the interplay between the physiological limitations of foragers and pheromone decay. Aphaenogaster senilis does not rely as strongly on chemical communication as T. nigerrimum. Chemical analysis of gaster extracts revealed the importance of C19 hydrocarbons in the trail-following behavior of A. senilis. However, increasing gaster extract concentration did not necessarily improve trail-following, and workers demonstrated important behavioral variability (Fig. 1). This species' foraging efficiency might, thus, rely on other kinds of cues such as physical contact with the leader (Hölldobler, 1971) and individual skills like load size (Cerdá et al., 1998b) or orientation ability, as in individual foraging species (Collett et al., 1992).

As far as the model species are representative, their mode of recruitment illustrates two different strategies. Mass recruiters like T. nigerrimum is based on an investment in chemical communication, allowing the rapid recruitment of numerous nestmates, and thereby the control of long-lasting food sources. However, variations in environmental conditions that affect pheromone concentration, such as hot ground temperatures, interfere with the recruitment process, and disrupt both the foraging and the competitive abilities (Cerdá et al., 1997). Group recruitment, on the other hand, allows the collective retrieval of short-lasting resources such as dead insects (Cerdá et al., 2009), but does not enhance competitive superiority. Notwithstanding, since foragers are not restricted by chemical cues, fluctuating environmental conditions do not affect their foraging activity.

At the community level, species coexistence might be promoted by these different investments in strength vs. flexibility, or competitive ability vs. abiotic tolerance. In Mediterranean-like communities, dominant species are able to displace subordinates but are less tolerant to high temperatures. This restriction is partly due to physiological limitations (e.g., the Critical Thermal Limit of T. nigerrimum is $4{ }^{\circ} \mathrm{C}$ lower than that of $\mathrm{A}$. senilis), but also to behavioral differences regarding foraging activity. However, this "dominant/subordinate" terminology might be somehow misleading: it contributes to the idea that subordinate species are maintained in the community by exploiting suboptimal niches. On the contrary, subordinates have an ecological niche with extended dimensions that allows them to face changing environmental conditions without losing efficiency.
Their strategy is, thus, fully adapted to fluctuating environments like terrestrial Mediterranean ecosystems.

We focused on the effect of high temperatures on trailfollowing behavior according to the kind of recruitment used by different species. In our model system, ants' trailfollowing was more altered by increasing temperature in the mass-recruiting species than in the group-recruiting species. This result suggests a functional mechanism for the Dominance-Thermal tolerance trade-off in semi-arid ant communities (Cerdá et al., 1998a; Wittman et al., 2010): since behavioral dominance relies on a species' ability to recruit nestmates, high temperatures, by reducing recruitment efficiency, might restrict dominance ability at the community level. Trade-offs between competitive ability and stress tolerance are common in many different communities (e.g., marine communities, plant communities) and it would be worth assessing the functional mechanism of such trade-offs in other systems to gain a better understanding of community diversity.

Acknowledgments We thank two anonymous referees for helpful comments. We are grateful to Jessica Pearce for revision of the manuscript (and English checking). Doñana National Park authorities gave permission to collect ant colonies. Experimental work in EBD have been funded by Spanish Ministerio de Ciencia e Innovación/FEDER (projects CGL2009-09690/BOS and CGL2009-12472/BOS). This work conforms to the legal requirements of the Spanish law.

\section{References}

Albrecht, M. and Gotelli, N. 2001. Spatial and temporal niche partitioning in grassland ants. Oecologia 126:134-141.

ANDERSEN, A. N. 2008. Not enough niches: Non-equilibrial processes promoting species coexistence in diverse ant communities. Aust. Ecol. 33:211-220.

Beckers, R., Goss, S., Deneubourg, J., and Pasteels, J. 1989. Colony size, communication and ant foraging strategy. Psyche 96:239-256.

Beckers, R., Deneubourg, J., and Goss, S. 1992. Trail laying behaviour during food recruitment in the ant Lasius niger (L.). Insect. Soc. 39:59-72.

Bestelmeyer, B. T. 2000. The trade-off between thermal tolerance and behavioural dominance in a subtropical south american ant community. J. Anim. Ecol. 69:998-1009.

Blight, O., Provost, E., Renucci, M., Tirard, A., and Orgeas, J. 2010. A native ant armed to limit the spread of the Argentine ant. Biol. Inv. 12:3785-3793.

BlÜTHGEN, N. and FIEDLER, K. 2004. Competition for composition: Lessons from nectar-feeding ant communities. Ecology 85:12791485.

Bonabeau, E., Theraulaz, G., and Deneubourg, J.-L. 1998. Group and mass recruitment in ant colonies: The influence of contact rates. J. Theor. Biol. 195:157-166.

Boulay, R., Hefetz, A., Cerdá, X., Devers, S., Francke, W., Twele, R., and Lenoir, A. 2007a. Production of sexuals in a fission-performing ant: Dual effects of queen pheromones and colony size. Behav. Ecol. Sociobiol. 61:1531-1541. 
Boulay, R., Carro, F., Soriguer, R., and Cerdá, X. 2007b. Synchrony between fruit maturation and effective disperser's foraging activity increases seed protection against seed predator. Proc. R. Soc. Lond. B 274:2515-2522.

CERDÁ, X. and RetanA, J. 2000. Alternative strategies by thermophilic ants to cope with extreme heat: Individual versus colony level traits. Oikos 89:155-163.

Cerdá, X., Retana, J., Bosch, J., and Alsina, A. 1989. Exploitation of food resources by the ant Tapinoma nigerrimum (Hym., Formicidae). Acta Oecol. 10:419-429.

Cerdá, X., Retana, J., and Cros, S. 1997. Thermal disruption of transitive hierarchies in Mediterranean ant communities. J. Anim. Ecol. 66:363-374.

Cerdé, X., Retana, J., and Cros, S. 1998a. Critical thermal limits in Mediterranean ant species: Functional trade-off between mortality risk and foraging performance. Funct. Ecol. 12:45-55.

Cerdá, X., Retana, J., and Cros, S. 1998b. Prey size reverses the outcome of interference interactions of scavenger ants. Oikos 82:99-110.

Cerdá, X., Angulo, E., Boulay, R., and Lenoir, A. 2009. Individual and collective foraging decisions: A field study of worker recruitment in the gypsy ant Aphaenogaster senilis. Behav. Ecol. Sociobiol. 63:551-562.

Collett, T. S., Dillmann, E., Giger, A., and Wehner, R. 1992. Visual landmarks and route following in desert ants. J. Comp. Physiol. A 170:435-442.

Cros, S., Cerdá, X., and Retana, J. 1997. Spatial and temporal pattern variations in the activity patterns of Mediterranean ant communities. Ecoscience 4:269-278.

Detrain, C. and Deneubourg, J.-L. 2002. Complexity of environment and parsimony of decision rules in insect societies. Biol. Bull. 202:268-274.

FresneAU, D. 1985. Individual foraging and path fidelity in a Ponerine ant. Insect. Soc. 32:109-116.

GEHRING, W. J. and WEHNER, R. 1995. Heat shock protein synthesis and thermotolerance in Cataglyphis, an ant from the Sahara desert. Proc. Natl. Acad. Sci. U.S.A. 92:2994-2998.

HöLldoBleR, B. 1971. Recruitment behavior in Camponotus socius (Hym. Formicidae). J. Comp. Physiol. A 75:123-142.

Hölldobler, B. and Wilson, E. O. 1990. The Ants. The Belknap Press of Harvard University, Cambridge, MA. 732 pp.

JAFFE, K. 1980. Theoretical analysis of the communication system for chemical mass recruitment in ants. J. Theor. Biol. 84:589-609.

Kohl, E., Hölldobler, B., and Bestmann, H. 2001. Trail and recruitment pheromones in Camponotus socius (Hymenoptera: Formicidae). Chemoecology 11:67-73.

LeBrun, E. G. 2005. Who is the top dog in ant communities? Resources, parasitoids, and multiple competitive hierarchies. Oecologia 142:643-652.

Lenoir, A., Nowbahari, E., Quérard, L., PondicQ, N., and DELALANDE, C. 1990. Habitat exploitation and intercolonial relationship in the ant Cataglyphis cursor (hymenoptera: Formicidae). Acta Oecol. 11:3-18.

Lenoir, A., Aron, S., Cerdá, X., and Hefetz, A. 2009. Cataglyphis desert ants: A good model for evolutionary biology in Darwin's anniversary year — A review. Isr. J. Entomol. 39:1-32.
Lenoir, A., Benoist, A., Hefetz, A., Francke, W., Cerdá, X., and Boulay, R. 2011. Trail-following behaviour in two Aphaenogaster ants. Chemoecology 21:83-88.

Lessard, J.-P., DunN, R. R., and SANDERS, N. J. 2009. Temperaturemediated coexistence in temperate forest ant communities. Insect. Soc. 56:149-156.

Lighton, J. R. B. and Feener, D. H. 1989. Water-loss rate and cuticular permeability in foragers of the desert ant pogonomyrmex rugosus. Physiol. Zool. 62:1232-1256.

Morgan, E. D. 2009. Trail pheromones of ants. Physiol. Entomol. 34:1-17.

Pavan, M. and Trave, R. 1958. Étude sur les Formicidae. IV. Sur le venin du Dolichodéride Tapinoma nigerrimum Nyl. Insect. Soc. 5:299-308.

R Development CoRe Team 2010. R: A Language and Environment for Statistical Computing. R Foundation for Statistical Computing, Vienna, Austria. ISBN 3-900051-07-0.

RetanA, J. and Cerdá, X. 2000. Patterns of diversity and composition of Mediterranean ground ant communities tracking spatial and temporal variability in the thermal environment. Oecologia 123:436-444.

Ruano, F., Tinaut, A., and Soler, J. J. 2000. High surface temperatures select for individual foraging in ants. Behav. Ecol. 11:396404.

SANDERS, N. J. AND GoRdon, D. 2003. Resource-dependent interactions and the organization of desert ant communities. Ecology 84:1024-1031.

SAVOlAinen, R. and VePsÄLÄINEN, K. 1989. Niche differentiation of ant species within territories of the wood ant Formica polyctena. Oikos 56:3-16.

Simon, T. and Hefetz, A. 1991. Trail-following responses of Tapinoma simrothi (Formicidae: Dolichoderinae) to pygidial gland extracts. Insect. Soc. 38:17-25.

Stefan, S. and Wehner, R. 2012. Leg allometry in ants: Extreme long-leggedness in thermophilic species. Arthropod Struct. Dev. 41:1-77.

Torres, J. A. 1984. Niches and coexistence of ant communities in Puerto Rico: Repeated patterns. Biotropica 16:284-295.

Traniello, J. F. A. 1989. Foraging strategies of ants. Annu. Rev. Entomol. 34:191-210.

van Oudenhove, L., Billoir, E., Boulay, R., Bernstein, C., and CERDÁ, X. 2011. Temperature limits trail following behaviour through pheromone decay in ants. Naturwissenschaften 98:10091017.

VAnder Meer, R. 2012. Ants: The supreme soil manipulators. J. Chem. Ecol. this issue.

Wehner, R., Harkness, R. D., and Schmid-Hempel, P. 1983. PP. 79, Foraging strategies in individually searching ants Cataglyphis bicolor (Hymenoptera; Formicidae). Akad Wiss Literat, Mainz, Germany.

WiLson, E. O. 1971. The Insect Societies. Belknap University Press, Cambridge.

Wittman, S. E., Sanders, N. J., Ellison, A. M., Jules, E. S., RATChFORD, J. S., AND GotelLI, N. J. 2010. Species interactions and thermal constraints on ant community structure. Oikos 119:551-559. 